\title{
Non-ordinary mental expressions (NOMEs): Clues on the nature of the human mind
}

\author{
Enrico Facco $^{1,2}$; Luciano Pederzoli ${ }^{1,3 ;}$ \& Patrizio Tressoldi ${ }^{1}$ \\ ${ }^{1}$ University of Padua (Italy) \\ ${ }^{2}$ Italian Center of Clinical and Experimental Hypnosis (Italy) \\ ${ }^{3}$ EvanLab (Italy) \\ Correspondence: patrizio.tressoldi@unipd.it
}

Copyright. 2021. Psychreg Journal of Psychology Published by Psychreg Ltd ISSN: 2515-138X

Psychreg

\begin{abstract}
The aim of this paper is to describe some ostensibly odd, non-ordinary mental expressions (NOMEs) that have been considered implausible, illusory or hallucinatory phenomena, possible symptoms of disorders of the neurological or psychological functioning. They include a large variety of phenomena, encompassing hearing voices, seeing presences, communication with non-incarnated entities (including channelling), transpersonal experiences, out-of-body experiences, near-death-experiences, previous life memories, presentiments and precognitions, seeing at distance, mind interactions at a distance, mind-matter interactions at distance. We think that individuals experiencing NOMEs should not feel like they were outsiders or diseased; they should feel free to talk about their uncommon experiences and be listen to with an open, not-judging mind, respecting the patients' experience and narration. In fact, NOMEs are non-pathological phenomena laying in a still misunderstood grey area between mental health and psychological or psychiatric disorders, while some of them suggest intriguing properties of human consciousness. Their ostensible incompatibility with some axioms and theories of consciousness, shows the inescapable epistemological implications of their proper investigation and understanding.
\end{abstract}

Keywords: altered states; anomalous experiences; consciousness: epistemology; non-ordinary mental expressions. 
The aim of this paper is to describe several intriguing phenomena of non-ordinary mental expressions (NOMEs) as well as conditions that may favour or elicit them and suggest a possible theoretical interpretation.

Cardeña et al. (2004; 2014) introduced the concept of anomalous experiences (AEs), to overcome the concept of altered states of consciousness (ASCs; see Vaitl et al., 2005). Later on, the term non-ordinary mental expressions (NOMEs) was introduced, to include a broader set of experiences, i.e., both non-pathological ASCs and AEs (Cardeña \& Facco, 2015; Facco, 2014; Facco et al., 2015; Facco et al., 2020). The term 'non-ordinary' emphasise their deviation from the adopted Weltanschauung (worldview) and avoids any prejudice or a priori idea of abnormality or ostensible oddity. Rather, it emphasises the diversity of these experiences with respect to what is conventionally admitted i.e., the epistemological and metaphysical implications raised by their phenomenology, description and study.

There is a trait d'union between several NOMEs - including hypnosis, meditation, mystical experiences, near death experiences (NDEs), end of life experiences and memories of previous lives (Facco, 2012; 2017; Facco et al., 2015; 2019c) a fact that calls for bringing them together under one roof, in order to properly understand their possible common elements, meanings and related mind-brain processes. NOMEs also include superior states of consciousness - including the spiritual self (James, 1958), the expansion or enlargement of the self (Arieti, 1967; Russell, 1912), the superconscious of Assagioli (1988), wisdom, sageness, and the concepts of enlightenment and epoptéia (elicited by the initiation to Greek mysteries and described by Aristotle in Eudemus, fr. 10) as well as similar states in shamanism.

The scientific study of NOMEs - as well as all subjective phenomena - calls for a neurophenomenological approach taking into account the first person perspective (1PP), encompassing its value and meaning and merging both first and third person perspectives (3PP) in a whole (Varela, 1996; Rudrauf et al., 2003).

\section{Epistemological and metaphysical aspects}

Different NOMEs, such as visions, prophecies, NDEs and mystical experiences, are suggestive of a different and wider reality than the one conventionally admitted by the current Weltanschauung, ruled by classical thought and materialist monism. Here, it is worth emphasizing that the monist materialist view adopted by mainstream neurosciences is metaphysical in nature and, as such, is based on undemonstrated axioms. As a result, none of the available hypotheses about life, death and reality - i.e., the materialist idea of a single, biological life doomed to become nothing or the idea of an afterlife (no matter which otherworldly dimension), and reincarnation - are more plausible, rational and/or truthful than the others (Testoni et al., 2017).

Despite being beyond the field of interest of positive sciences, they are no less relevant and concrete in the comprehension of the meaning of life and its doom. Likewise, all formal axiomatic theories and disciplines (starting with mathematics) include statements which can neither be proved nor disproved, according to Gödel's Theorems of Incompleteness (Raatikainen, 2018), a fact also showing the limits of the mathematical apriorism at the base of Galilean sciences. It is therefore necessary to maintain a profound humility and the Socratic awareness of knowing that we do not know, in order to maintain an appropriate open-mindedness. One should also refrain from rejecting a priori anything looking ostensibly odd on the basis of the adopted axioms and theories, a temptation woefully witnessed by the universal presence of detractors in the history of science.

Materialist monism is a partial, self-contradictory metaphysical stance, unable to comprehend subjective phenomena and everything looking 'immaterial'. Its limits should be overcome by merging materialist monist and dualist stances in a higherorder integration - which has been named by different authors neutral monism, dual aspect-monism, whole monism or holomonism (Facco et al., 2017; Panksepp, 2005; Studenberg, 2018). On the other hand, the claimed transcendent realities held by dualists look like a sort of nowhere lands; perhaps, it is more reasonable to assume that we are simply blind to what is beyond our apparent horizon. As the history of scientific revolutions teaches us (Kuhn, 1962), it would not be surprising if some phenomena viewed today as implausible and belonging to the uncertain world of parapsychology or science fiction would turn out to be real. As Schopenhauer wisely stated, 'truth is born as a paradox and dies as the obvious'.

NOMEs are a universal phenomenon of the human mind, present in all cultures since prehistoric times. They are the result of its still elusive physiology and its relationship with an unknown world in the extraordinary effort to probe the unsolved mystery of the meaning of life and death, in the geometry of an equally mysterious space-time. Thus, a proper understanding of NOMEs calls for an interdisciplinary approach, including neuroscience, philosophy, anthropology and physics. Being real facts (though 'immaterial' mental ones), they are undeniable, while their interpretation has deep epistemological and metaphysical implications, which cannot be properly addressed or resolved within the limits of a narrow materialist-monist and mechanistreductionist approach. Their phenomenology is therefore a challenge to the ruling paradigm of medical science. In other words, NOMEs reintroduce the dilemma of the mind-brain-body-reality relationship as well as the huge metaphysical problem of knowledge, in the definition and dialectic between truth-reality and falsehood-illusion, certainty and faith-belief, a problem underscoring the limits of human capacity and adopted paradigms to grasp the truth, if possible (Testoni et al., 2017).

\section{Non-ordinary experiences}

The major non-ordinary experiences, all of which share some common element, will be shortly outlined here and their possible interpretations will be discussed. 


\section{Hearing voices}

'These entities, often dead (even animals) "transmit" messages to me in the form of images (luminous figures) and thoughts. They don't appear in particular moments but unpredictably, especially when I feel more receptive. The otherworldly spirit belongs to a non-negative world, where there is no judgment, and it manifests itself so that I can be a go-between with a person, sometimes even a stranger.'

This is a simple example of a wide range of experiences, the common feature of which is the perception of voices directly speaking to the subject and perceived as belonging to other identities. Needless to say, such experiences are often traumatic when they occur in healthy people, since they may be easily taken for symptoms of psychiatric disorders, such as psychosis and dissociative personality disorders. In fact, for the most of the 20th century, auditory hallucinations where considered as a pathognomonic symptom of schizophrenia.

Mercifully, these experiences have been increasingly studied in non-clinical populations since the 1980s, in order to better understand their features and prevalence, as well as improve their management and prevent the risk of developing severe discomfort or psychiatric disorders (Holt \& Tickle, 2014; Iudici, et al., 2019; Salvini \& Stecca, 2013). 'Voice listeners' themselves have greatly contributed to the better knowledge of these ostensibly odd phenomena often in collaboration with mental health professionals - especially the Dutch psychiatrist Marius Romme. In doing so, they have encouraged mutualhelp and direct information meetings, which have fuelled the international Hearing Voices Movement and the Hearing Voices Network (www.hearing-voices.org).

At this time, it seems more reasonable to define hearing voices as an extension of the normal inner speech, misattributed to other identities and to take into account that inner speech is an essential activity for cognition and metacognition, planning and making decisions, as well as evaluating, knowing and motivating oneself (Facco et al 2019c).

\section{Seeing presences}

'I had the cat in front of me looking at me, and suddenly we both turned to the door of the room. There was a man with dark hair and black eyes looking at me. The thing that struck me the most this time, compared to the other experiences I had, is that it was in the flesh: the other times it was in an ethereal, let's say impalpable form. The cat started chasing him, and the man turned around and left. The doors and windows were closed, it was evening after dinner in autumn/winter. He hit me because he was real flesh and blood, so much so that I thought he was a thief. He had a stern look, but not aggressive. '

While experiences of this kind are not uncommon in people who are experiencing the recent bereavement of a loved one (Cooper, Roe and Mitchell, 2017; Tressoldi et al., 2022), they can also be experienced by other people who are not in psychological or physical conditions able to foster illusions of this kind (Badcock et al., 2017).

\section{Communication with non-incarnated entities}

The desire and practices to communicate with people who have concluded their life experience on our earthly dimension goes back to the origins of humanity and likely developed in parallel with religious, spiritual and cultural beliefs, suggesting a continuity of existence after the death of the physical body. In ancient Egypt, a clear concept of death as a transition to another dimension had already been well described in the Pyramid Texts (dating back to 27th-22nd century BC), the Sarcophagus Text and the Egyptian Book of the Dead. Likewise, since the beginning of Indian culture the âtman (individual soul) was considered as a part of the universal Atman. The Bardo Thödol (Tibetan Book of the Dead, dating back to the 8th century BC) describes both a coarse consciousness, closely connected to the brain and dying with it (akin to the Western scientific view) and a surviving subtle mind-energy moving toward its ultimate existence or doomed to reincarnation. According to Hippocrates, everything unceasingly changes and all things are interrelated, no one being endowed with an autonomous, independent, intrinsic existence: rather, they are simultaneously concordant and contrary in their transformation (De Diaeta, I, 3-5). He also warns against the view that everything comes out of Hades and returns to Hades an opinion of people trusting in their eyes rather than their reason for 'nothing which is living can die, and it is impossible that what is not may start to be ' (De Diaeta, I, 4, 9).

In her review on the different forms of communication after death, Julie Beishel (2019) classifies those with other entities as spontaneous, facilitated, assisted and requested. Spontaneous ones are those occurring without a clear intention, but only following a simple desire for this to happen. Instead, facilitated and requested communications are experiences sought through specific techniques, such as the use of psychotropic agents or the use of equipment or other tools supposed to facilitate the communication with disembodied entities. The most widely known devices are probably voice recorders - a topic also known as psychophony, metaphony or instrumental transcommunication. However, there is no evidence of the effectiveness of these techniques to date.

The study of assisted communication through mediums - or, say, people claiming to have this ability - has obtained some evidence in recent years. Julia Beischel and Mark Boccuzzi and others attempted to check the alleged information provided by mediums by devising experimental designs with the maximum of blindness, in order to prevent them from obtaining information either indirectly from the applicants or by conventional sources, such as internet (Beischel et al., 2015; Beischel \& Zingrone, 2015; Beischel et al., 2017; Tressoldi et. Al., 2021). 
Currently, the analysis of all published studies until 2019 suggests that some of the investigated mediums may have unconventional access to information about the deceased (Sarraf et al., 2020). Nevertheless, the origin of this information retrieval remains unclear at best; it has been interpreted as depending on alleged telepathy, retrieval from hypothetical sources of universal memory storing all individual experiences, or non-local properties of consciousness-information.

\section{Channelling}

Another modality of communication with non-incarnate entities is through so-called channelers, i.e.. people who make their voice and body available for communication from alleged entities, including both deceased persons and non-earthily beings (Pederzoli et al., 2021).

Leaving aside the history of these phenomena, which also goes back to the dawn of religions and other cultures, recent scientific research has started to investigate the origin of this information, examining whether it may spring from the channeler (such as implicit memory and unconscious sources of information), rather than a hypothetical external intelligent sources. On the other hand, this is hardly possible, being a matter of a subjective channeler's report devoid of any possible objective confirmation. For example, should the channeler report messages from an alleged angel or an unearthly entity, one cannot obviously check whether it is a "real" entity; rather (and more reasonably) it might result from his/her inner world and its projection into the outer world. Therefore, any report of channelling should be interpreted by taking into account its meaning and value without attributing it to any alleged external identity.

A further step to check the source of channelers' information has been attempted by the Hypno-Channellings research programme (Pederzoli et al., 2018). By hypnotically inducing an OBE in the channeler followed by a contact with a discarnate entity, it is possible to interview this purported entity through the channeler's voice. Of course, the content of these interviews could still reflects channeler's and/or hypnotist's mind (the latter through direct, indirect or subliminal suggestions), while any proof of facts that both the channeler and the hypnotist cannot know would undoubtedly show something more than a simple projection from their inner world.

A short excerpt from the interviews with the entity named 'Him' (the text can be read in full in "Contents of the interviews with 'Him ', available at https://doi.org/10.6084/m9.figshare.6984251.v15) is reported below:

'LP [the hypnotist] asks how long, after the extinction of the Physical Body and the Subtle Body, our identity that can be contacted by mediums persists. He also asks how long he can be contacted while he is processing the next incarnation. "He" specifies that these are two different situations. In the former, the Subtle Body is sometimes not well 'synchronized', especially with the passage represented by death, and both a better synchrony and a period of re-elaboration of the experience acquired in life just ended would be desirable, before the possible subsequent incarnation,. Rather frequently the Subtle Body remains, however, after the death of the Physical Body. According to 'Him' it is an anomaly because it shouldn't happen, but that is a temporal phase of quite easy contact: you contact the Subtle Body. When there is a strong emotionality on the part of loved ones, the Subtle Body is influenced by it and finds it difficult to disappear.'

Clearly, the above information is nothing more than the channelers' opinion, far from showing the possibility of communication with entities in other hypothetical realms. Nonetheless, the Hypno-Channelling procedure can be used to explore these ostensibly odd mental facts and check some of their phenomenological and physiological correlates, as done for example by Wahbeh et al., 2018; Wahbeh et al., 2019; Wahbeh \& Radin, 2018.

\section{Transpersonal Experiences}

Unlike contact with disembodied entities, transpersonal experiences - also called mystical or spiritual experiences - refer to a direct contact or union with a primary spiritual principle, named in different ways according to the ethnic and socio-cultural background (e.g., God, Ātman, Allah or any other entity). Here is an excerpt of a recent case studied by Facco et al. (2019a):

'We are essences/essences of love Almost reunited with the whole thing... I feel myself a current that has flowed and passed through. We are all reflected in the same light... acknowledgement of being a spirit... And I see my outline of semi-opaque light superimposed on the outline of full light in which we are immersed... I see the silhouette Me in the Whole's silhouette And I mean Spiritual Peace... ... And I mean that we are individual cells of the same spirit... In each one is imprinted the DNA of the Spirit... but each one lives to accomplish more than herself... And I mean... ...each one of them completing themselves and the life of the entire organism... ... and as I pray I see my unfinished body thinning as the Essence of God's Imagination Similarity expands...'

These experiences, with their fusional flavour, allow one to overcome the usual dualistic separation between the self and the outer world and realize to be an inseparable part of it. They are closely related to the above-mentioned enlargement of Self, an example of which is the outstanding NOME that Federico Faggin the inventor of computer processors has described in his autobiography (Faggin, 2019):

'When I went back to bed, as I waited in silence to fall asleep again, I felt a powerful charge of love energy emanating from my chest, that I had never felt before. 
'This feeling was clearly love, but a love so intense and so incredibly fulfilling that it outweighed any idea or experience of mine about the nature of love. I perceived it as a wide beam of white, glittering, vivid, blissful light bursting from my heart with incredible strength. Even more incredible was to experience that the source of that love was me!

'Suddenly that light exploded and filled the entire room and then expanded to embrace the entire universe with the same white splendour. Then I knew without a shadow of a doubt that this was the 'substance' of which everything that exists is made. It was what created the universe from itself. To my great surprise, I recognised that light was me! The whole experience lasted perhaps less than a minute and changed me forever.'

These experiences are mainly spontaneous, as in the above-mentioned cases, but they may also be elicited by specific procedures, such as meditation (Chen et al., 2011) or by the controlled intake of psychotropic agents, such as psilocybin (Griffiths et al., 2008) or ayahuasca (Bresnick \& Levin, 2006; Trichter et al., 2009).

\section{OBEs}

Spontaneous OBEs in physiological conditions are reported by an average of about $9 \%$ of respondents and up to $26 \%$ of people, who claim to have experienced at least one OBE in their lifetime (Alvarado, 2015; Braithwaite et al., 2011). Only rarely are these experiences voluntary, a fact making hard any scientific investigation into their physiological and phenomenological features (Carruthers, 2015; Smith \& Messier, 2014).

This limitation may be at least partially addressed with hypnotically induced OBEs (H-OBEs) (Facco et al., 2019b; Pederzoli \& Tressoldi, 2018). The advantage of $\mathrm{H}-\mathrm{OBE}$ is the possibility to study its neurophysiological correlates as well as to interview the participants and administer them psychological tests during their experience, in order to investigate their phenomenological features and compare them to the ordinary state of consciousness.

H-OBEs have been recently compared to OBEs imagined in a state of ordinary consciousness (I-OBE) (Facco et al., 2019b). The results showed significantly higher scores of the altered state, positive affect, altered experience, and attention subdimensions of the Pekala Consciousness Inventory in H-OBE than in I-OBE; unlike I-OBE, H-OBE was associated with a significant power decrease in beta and gamma EEG activity in the right parieto-temporal derivations.

This technique also allowed to detect OBE-related changes in the experience of vision, time and movement (De Foe et al., 2017; Tressoldi et al., 2014, 2015, 2021): (a) 'I see it [an object] a little bit all at the same time, then, as I think about going through it, I see the inside too. The body sees in three dimensions, while in this state I perceive by intuition all its essence, including all the information about the object; (b) 'I do not perceive any sense of movement from one place to another, but a sort of immediate displacement with the Psychic Body'; (c) 'It is as if time had stopped. I feel really good. I can move right, left, above and below in a non-concrete space that seems to be infinite. I can also go to another space, darker and more concrete, and move there as I like. '

\section{Near-death experiences}

NDEs are the best known and most intriguing NOMEs. Despite being real clinical facts with a clear phenomenology and epidemiology, NDEs have been a priori rejected or reduced to a matter of brain going awry, according to the ruling materialist approach of medical science. Being placed at the boundary between life, death and hereafter, NDEs also clashed with the doctrine of the Two Magisteria, held by Pope Pius XII and later on endorsed by the American Academy of Sciences of USA as well (Alberts, 1998; Facco et al., 2015; Parnia et al., 2017).

Fortunately, following the seminal work of Moody Jr. $(1977,1980)$ an increasing interest has developed at the end of the last century and a wealth of data are now available in the literature. NDEs occur during life-threatening conditions (e.g. cardiac arrest and haemorrhagic shock) with loss of consciousness, but have also been reported in non-critical conditions as well, such as during haemodialysis or during severe psychological distress (Charland-Verville et al., 2014; Facco \& Agrillo, 2012a, 2012b; Gabbard, Twelmlow \& Jones, 1981;Lai et al. 2007).

Their main features are now well known and can be summarised as follows: (a) awareness of being dead; (b) OBE; (c) passage through a tunnel ending in a non-ordinary dimension, where visual and auditory perceptions seem to be enhanced; (d) experience of great peace and well-being, immersed in a celestial landscape or a light emanating a feeling of great bliss and love; (e) meeting with deceased relatives and/or non-defined entities, often reported as beings of light; (f) Holographic life review; (g) perception of a limit not to be trespassed, often with someone (entity or deceased relative) warning them to go back because his/her mission has not ended yet; (h) return to the physical body with a clear awareness that it was not a dream or a hallucination, but a real experience; the return is usually unpleasant, given the gap between the profound bliss during the NDE and the post-critical clinical condition; (i) an indelible memory and lifelong positive permanent effects on the meaning of life and death, leading to self-transformation and the fear of death being overcome.

Several hypotheses have been advanced in recent years in an attempt to provide a neurobiological interpretation of NDE features. However, none of these hypotheses has been demonstrated so far, while some of them are ill-founded, being contradicted by already known facts. The main available hypotheses will be only listed here, for the sake of concision (for further analysis see Facco, 2018; Facco \& Agrillo, 2012b; Facco, et al., 2015): (1) retinal ischaemia as a cause of tunnel vision; (2) acidosis and ionic shift; (3) increased release of endogenous opioids, glutamate and/or other neurotransmitters as 
well as administered drugs as a cause of changed emotional state and hallucinations, equating NDEs to delirium; (4) REM intrusions, equating NDEs to hypnagogic or hypnopompic hallucinations; (5) temporal lobe epilepsy; (6) residual EEG activity during cardiac arrest; (7) dysfunction of the parieto-temporal junction as a cause of OBEs; (8) psychological interpretation (i.e., expectation of hereafter).

Very uncommon well-documented cases were able to witness what happened in the emergency room during their cardiac arrest from outside their body. In the last of these cases, it was also possible to estimate the persistence of consciousness for at least three minutes during ventricular fibrillation (Sabom, 1998; van Lommel et al., 2001; Parnia et al., 2014).

Besides checking NDEs in real time as soon as the patients regains consciousness, they may be studied by reliving them during hypnosis (Palmieri et al. (2014; Martial et al., 2019). Palmieri et al. (2014) have used hypnosis and EEG monitoring to improve recall and decrease memory inaccuracy in patients with previous NDEs, as well as check their neural markers compared to memories of both real and imagined events. NDE memories were similar to real memories and differed from memories of imagined events as regards detail richness, self-referential and emotional information. Their EEG correlates were also significantly different from memories of imagined events, being associated with theta (a well-known marker of episodic memory) and delta band activity (related to mental activities like the recollection of the past, as well as trance states, hallucinations, and other related portals to transpersonal experiences). In short, NDE memories are stored as episodic memories of events experienced in a peculiar state of consciousness.

\section{Previous life memories}

Likewise NDEs, memories of previous lives seem ostensibly odd, appearing to be closely related to philosophies and religions extending far beyond the perspective of positive sciences and even beyond the sphere of the monotheist Abrahamic tradition.

The memory of past lives suggests the idea of reincarnation, but they prove nothing. On the other hand, reincarnation is neither less rational nor plausible than the idea of a single life (with or without hereafter). In Western culture the belief in the reincarnation was held by Pitagoras and Plato (see the myth of Er), and by Origen (3rd century A.C.) in Christendom, but was then withdrawn by the Church following the Synod of Constantinople in 543 A.C. Thus, its disappearance from Western culture reflects nothing more than a cultural filter engendered by the doctrine of the Church, while the East, especially India, has always held it.

The problem of reincarnation calls for a rigorous rational approach and a genuine philosophical perplexity, while the memories of previous lives are real clinical facts in themselves, neither demonstrating nor disproving any philosophical assumption. As a result, the duty of scientific research is to analyse them without prejudices of whatsoever origin (including scientific ones), in order to facilitate their comprehension.

The problem of previous lives is twofold: a) spontaneous memories, especially in small children; b) hypnotic regression to previous lives.

Following the pioneering work of Ian Stevenson (1960, 1977), over 2500 children (mainly pre-schoolers) reporting memories of other deceased identities have been described to date, including Western children, i.e., people belonging to a culture which does not admit reincarnation. The available data show the following facts (see Mills \& Tucker, 2014 and Tucker, 2008 as reviews): (a) Spontaneous memories arise at an average age of three years and are forgotten during school age, like many childhood memories; (b) The data recorded in several cases allowed Stevenson to verify the truthfulness of memories and trace the identity of the deceased person, in the majority of cases resulting in a violent death; (c) Some children have intriguing marks and/or birth defects corresponding to the site of the injury causing the death of the perceived identity (e.g., the entry wound of a bullet); (c) A 16-month median elapsed time between the death of the recalled identity and the child's birth has been estimated; (d) The memories mainly deal with the last part of the previous life and are associated with strong feelings; (e) Some children's behaviors seem to be coherent with the reported previous life, including affection for family members in the previous life and symptoms similar to those of post-traumatic stress disorder (e.g., fear of water when the previous identity died by drowning); and (f) The psychological profile of these children shows greater verbal skills, better memory and school performance and more social activity than their peers and no meaningful psychiatric symptoms (Haraldsson, 1995, 2003).

Matlok's recent book (Matlok, 2019) and other articles on individual cases (Masayuki, 2017; Tucker, 2016), also support the reality of this kind of experience. In conclusion, the memories of past lives are clear, undeniable facts, calling for a proper interpretation.

Hypnotic regression to alleged previous lives looks to be a much simpler phenomenon generally unrelated to genuine facts and, therefore, may be regarded as a matter of pseudomemories. The capacity to report previous lives is also related to hypnotisability, cultural and religious background and higher scores on measures of magical ideation and absorption (Meyersburg et al. 2009; Pyun \& Kim, 2009; Stevenson, 1994). On the other hand, the fact of being pseudomemories does not exclude their meaningful content, in that they may arise as imagined and conceptualized symbolic representation of anoetic emotions and contents springing from the unconscious, in order to make them noetically definable and tellable (Facco et al., 2019c). If so, they could aid psychotherapeutic interventions in exploring patient's unconscious in a way akin to dream interpretation. 
To the best of our knowledge, only two cases of veridical memories have been reported in the literature on hypnotic regression to past lives. The former was a patient reporting an intriguing correspondence between his uncommon medical conditions and past life memories, of which no satisfactory interpretation is available (Lucchetti et al. 2013). The second case was an American woman who recalled the identity of a Spanish woman named Michaela Maria Ruiz de Prado who lived during the 16th century. The report was very detailed and included several facts never published in English, some of them retrievable only in Archives in Cuenca (Spain) (Tarazi, 1990; an excerpt can be found at https://psi-encyclopedia.spr.ac.uk/articles/antonia-case-studyanalysis).

\section{Presentiments and precognitions}

According to the Merriam-Webster dictionary, presentiment is defined as 'a more or less obscure, vague, indefinite sensation of what might happen. ' When dealing with sensations, one must take into account their psychosomatic nature, including both emotions and physiological aspects such as cardiac, respiratory and digestive symptoms. Here, we shall refer only to those not depending on more or less conscious reasoning processes, i.e., related to expectations stemming from prior knowledge. For example, when we often travel a road with dangerous intersections, we may have a feeling of someone entering our lane, a feeling which may be favoured by our previous experience. Instead, no previous experience may justify a more or less conscious, vague emotion of discomfort occurring when we walk a familiar, safe path and then realize that the roadside has fallen away a little further ahead. In other words, the core of the problem is if and how one can anticipate rare and unpredictable events.

Despite the anticipation of random unpredictable future events being considered impossible, some evidence of this phenomenon has been collected in recent years by checking physiological reactions a few seconds before the administration of pleasant or unpleasant random events e.g., car accidents or gun shoot in the face (Duggan \& Tressoldi, 2018; Mossbridge et al., 2012).

The essential difference between presentiments and precognitions is that in the latter, one is aware of it and can thus translate it into thoughts and words, for example:

'I was 15 and it was Sunday. I was in the bathroom, and I was about to get in and out. At one point, a voice behind me told me to come out later. It hit me very hard, I looked back but obviously nobody was there. After 15 minutes, my grandfather's desperate screamed from the ground floor. He was feeling sick while my grandmother was passed out. I stepped in immediately, diagnosed a poisoning from the furnace, and saved their lives. If I had gone out at the usual time, they would have died.

Despite appearing to be uncommon and/or odd, these kinds of phenomena can be scientifically studied. Storm et al. (2017) reviewed 50 studies aiming to scrutinize the ability to perceive information related to a particular image, while dreaming. The results clearly revealed that the identification rate of the correct images was significantly higher than would be expected by chance.

\section{Seeing at a distance}

Unlike precognition, seeing at a distance or 'Remote Viewing' (a very popular term on the internet), is defined as the conscious and voluntary ability to collect information about objects, people, places, regardless of distance and time and any possible barrier able to mask them.

Let us report a well described example dealing with an experiment performed on 3 November 2003 about six weeks before the capture of Saddam Hussein with a group of experts in this technique (Schwartz, 2018). The participants were asked to describe the location and circumstances of Saddam Hussein at the time his location would have become known to American forces. The participants' imagined location was the following:

'Saddam will be found "underneath an ordinary looking house. It is on the outskirts of a small village, near Tikrit. '

'The house is part of a small complex; delimited on one side by a dirt road and, at the back, by a nearby river.'

'The house can be identified because it has a large tree growing at both ends and has a strange kind of partial second floor above the front door.'

Figure 1 shows a photo of the place where Saddam Hussein was captured (released by the US Department of Defense), including many details described during the remote viewing.

Figure 1: Photo of the place where Saddam Hussein was captured, released by the US Department of Defense (from Schwartz, 2018).

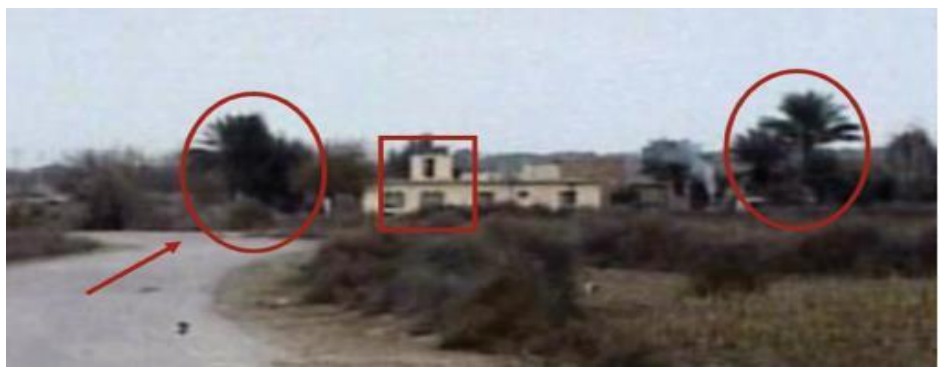


An example like this is incapable of establishing the reality of this phenomenon, but still remains intriguing.

The Star Gate project (conducted from 1972 to 1995) is one of the most famous projects using remote viewing for US intelligence purposes (all information can be found in Marwaha and May 2017, 2018).

This project was funded with approximately $\$ 20$ million, but the American Institutes for Research declared that the psychicspy operation had been a bust. On the other hand, Jessica Utts, president of the American Statistical Association, correctly emphasized that establishing the reality of the phenomenon is a different problem from that of examining whether it may be useful for government purposes (Utts, 1996). As far as the former is concerned, in her analysis she reported that there is no doubt that 'Using the standards applied to any other area of science, it is concluded that psychic functioning has been well established.'

Remote viewing has also been used in archaeology, such as in the recovery of the American brig Leander, sunk in 1834 while en route from the island of Cuba to Boston, Massachusetts (Schwartz \& De Mattei, 2000). Other studies suggest the possibility to predict stock market fluctuations above chance, (Kolodziejzyk, 2013; Smith et al., 2014), while others fail to show any positive result (Katz et al., 2018).

Remote viewing has also been used in police investigations, the most outstanding of which is the kidnap of American Brig. Gen. James D. Dozier by the Red Brigades in Italy on 17 Dec 1981. The Washington Post published an article by Sally Squires entitled The Pentagone's Twilight Zone on 17 April 1988, reviewing it and concluding that it was unsuccessful. On the other hand, a released CIA report confirms the use of remote viewing and its success: 'On 18 December, we conducted our first session... This is a drawing of the first session which was sent to Italy... The search for General Dozier should be concentrated in the Padua area... This briefing was done two days prior to General Dozier's actual rescue...Among other information obtained in a session on 21 December was the following... The only city found in northern Italy to contain a unique circle park with a cathedral was Padua... 8 days prior to his release, the remote viewer named the location of Gen. Dozier as Padua' (https://www.cia.gov/library/readingroom/docs/CIA-RDP96-00788R001700270020-4.pdf).

\section{Mind interaction at a distance}

Mind to mind interaction at a distance belongs to what is commonly named telepathy, which refers to shared information between people not attainable by conventional means.

At the end of 2020, 113 effect sizes on the Ganzfeld protocol were available and freely accessible for independent analysis (Tressoldi \& Storm, 2021). This protocol maximizes the visual and auditory isolation of participants, in order to check their capacity to identify what their partner saw or heard at distance in a separate room. As a whole, these studies showed the capacity of isolated subjects to identify their partner's perceptions with on average a 7\% higher than chance.

The mental connection between isolated coupled subjects may also involve unconscious processes, such as EEG changes, yielded by visual and/or auditory stimulation in the participant (the transmitter) located at a distance in another isolated room (Bilucaglia et al., 2019; Tressoldi et al., 2014, 2016; Giroldini et al., 2016, 2018).

The hypothesis of mind interaction stems from the possibility of non-local properties of consciousness, a huge problem raised by quantum physics. Perhaps, the world at large is less "local" than believed so far and nature might reveal itself as a huge integrated, complex system made of interrelated events including all living creatures (Atmanspacher, 2014, 2015; Barlow, 2015; Charlton, 2007; Connolly, 2015; Neppe \& Close, 2015; Walach \& Romer, 2011; Wang et al. 2013).

In conclusion, the idea of mind-to-mind interaction at a distance, despite being ostensibly odd when observed by the traditional positivist-materialist approach anchored to classical physics, might be more plausible and real than commonly believed and worth of further investigations to explore and better understand it.

\section{Non-ordinary interactions of consciousness}

The non-ordinary interactions of consciousness include the interaction on human behaviour, health, as well as organic compounds and electronic equipment. An example of possible non-ordinary interactions on human behaviour is the so-called 'Maharishi effect' named after Maharishi Mahesh the Indian yogi founder of transcendental meditation and Maharishi University in the US. The Maharishi effect claims that population's behaviors and/or negative events might be affected by transcendental meditation exercised by a number of meditators equal to approximately the square root of $1 \%$ of this population ( e.g. 100 meditators would be enough for a population of 1.000 .000 people), a formula based on the Hagelin's quantum field theoretical model (Hagelin, 1987). According to this hypothesis, the simultaneous deep meditative state in many subjects would create a field of psychophysical coherence for the entire population, reducing the number of negative events, such as assaults, rapes, road accidents, etc. 
Empirical support for this theory has been found in more than 50 studies (e.g., Cavanaugh \& Dillbeck, 2017; Dillbeck \& Cavanaugh, 2016, 2017; Orme-Johnson \& Oates, 2009). Indeed, the strange, ostensibly esoteric idea of mental interaction is much more common than traditionally believed, since it is not different in principle from the routine practice of prayer in all religions; in fact, prayer is routinely recommended by priests and jointly exercised by worshippers to help saving humanity from wrong behaviours and disasters.

The practices of healing and intercessory prayer involve vary widely according to ethno-cultural and theoretical models. For example, in Reiki and pranotherapy, healing is understood as a direct relationship between practitioners and patients able to channel the vital energy, while in theistic religious models, healing is obtained through the relationship with the divine and its power (a thousand-old view, form Imhotep temples in ancient Egypt to Lourdes).

Given the difficulties of conducting controlled clinical trials (including the placebo group), there is little evidence to support these remote interactions. Only a few meta-analyses on distant healing are available providing, as expected, contradictory results (Astin et al., 2000; Hodge, 2007; Masters et al., 2006). Besides their intrinsic limits and pitfalls, the lack of meaningful results also depends on the great differences of the adopted techniques and goals, encompassing many physical as well as psychiatric disorders. In this regard, the study of the effects of healing intentions on animals seem to be more interesting, animals being presumably less influenced by expectations and, thus, the placebo effect. For example, Bengston et al. (2007, 2012, 2018), reported the healing of lab rats that had been injected with lethal cancer cells, by exercising simple mental techniques centered on the intention to heal and a mental connection to the animals to be healed, without any direct contact.

Several studies on mental interaction on the growth of organic material, such as plants, seeds and cell cultures, seem to provide better results than those on humans. In the last meta-analysis, 49 of these experiments were analysed by Roe et al., (2014). Among these, a study investigated the effects of 'energy-charged' cotton, hands-on treatment by healers or their recorded voice on breast cancer cells in vitro. Surprisingly, the authors found a significant downregulation of ATP citrate lyase and interleukin $1 \mathrm{~b}$ after 4 and 24 hours of exposure to the recording in three independent experiments and concluded that: (a) the effect was reproducible; (b) healing intention can be captured and released; (c) hands-on delivery of healing intention is more effective than recording (Beseme et al., 2018). Furthermore, Radin et al., (2007) and Shiah \& Radin, (2013) in a double-blind, randomized, placebo-controlled experiment using chocolate exposed to good intentions by a group of meditators reported a significant improvement of mood and a decline in fatigue only in the intention group.

Studies on mental interaction with electronic equipment, mainly random number generators, date back as far as the $1930 \mathrm{~s}$ (Duggan, 2019), and a review of more than 300 studies has been published by Bösch et al. (2006). The latest developments in this line of research aim to: a) better understand the role of the mind on subatomic particles, such as photons (Radin, Michel, \& Delorme, 2016; Radin, Michel, Johnston, \& Delorme, 2013; Radin, Bancel \& Delorme, 2921; Tressoldi et al., 2016) and b) investigating the possibility of building up mentally controlled electronic equipment (Tressoldi et al., 2020).

\section{Clues about the nature of the human mind}

The aforementioned data reported above, deal with intriguing but ostensibly odd phenomena, which have been rejected a priori by positive sciences, due to the incompatibility with the adopted Weltanschauung. Nevertheless, they are 'real' mental nonpathological facts requiring a proper explanation. In the comprehension of NOMEs two options are possible: (a) all of them are fancies and should simply be discarded and, (b), their oddity at least partly depends on the ruling paradigm, a huge epistemological problem. In fact, science, as any other rational discipline, is metaphysically grounded on plausible but undemonstrated axioms and can only perceive and check what is compatible with them. In other words, seeing means simultaneously being blind to what is beyond the field of view as it has been well painted by a famous anecdote dealing with a man under a street lamp looking for the house keys he lost elsewhere, because that was the only place where he was able to see.

The 20th century physics has undergone a radical revolution and a shift of paradigm in order to understand the ostensibly absurd properties of space-time and matter-energy. Perhaps, medicine and psychology, which are still anchored to the physics of the 19th century, will begin to undergo a similar rethinking of their paradigm in the near future. A clue to this possible change is the recent introduction of quantum biology and quantum theories of consciousness (Lambert et al., 2013; Mohseni et al., 2014; Poznanski et al., 2017). If this is the case, a new rigorous scientific perspective may open up, allowing researchers to better understand some of the phenomena described above. We do not claim anything about their truthfulness, apart from the need to face what looks ostensibly odd with a rigorous scientific, open-minded approach, in order to comprehensively examine it. It also calls for a genuine sceptical stance, according to the original Greek meaning of the term $\sigma \kappa \varepsilon ́ \psi 1 \zeta$ (skèpsis), - i.e., reflection, search, refusal of dogmas of whatsoever origin (even scientific ones) and the nurture of a rigorous doubt neither admitting nor excluding anything a priori. Any other stance is subjected to dogmatic drift and ideology, leading to two possible opposite flaws: a) to implicitly trust non-existent phenomena and, b), to a priori neglect existent ones. Both of them are affected by a similar though opposite dissociation from reality.

All NOMEs, if properly understood, may shed much light on the true nature of the human mind and the mind-world relationship. Nonetheless, NOMEs cannot only be faced by a narrow mechanist-reductionist paradigm only, rather, they call for a neurophenomenological approach taking into account the content and meaning of subjective experience. 
Some NOMEs, like the intriguing experiences of previous lives, lay as non-pathological phenomena in a continuum between normal consciousness and dissociative identity disorders. The interplay between their neurobiological base, experience and introspective activity provide the base of inner life and its relationship with the outer world (Facco et al., 2019c).

Finally, the objectivism of positive science may result to be a 'transcendental naivety', as Husserl (1970) defined it. In fact, science in itself is a product of the human mind aimed to provide the most rigorous rational knowledge. As such, it inhabits and lives in the world of consciousness, the nature of which is irreducibly subjective, while the so-called objectivity cannot trespass the boundaries of shared subjectivity. This should be enough to start overcoming the century old Cartesian split between res cogitans and res extensa still adopted by both dualists and materialist monists, an essential step to better comprehend the consciousness and its place in the world.

\section{REFERENCES}

Alberts, B. (1998). Science and creationism. A view from the National Academy of Sciences. Preface. In National Academy of Sciences Staff. (pp. viii-ix). National Academic Press.

Alvarado, C. S. (2015). Out-of-Body Experience (OBE). In Psi Encyclopedia. London: The Society for Psychical Research.

Astin, J. A., Harkness, E., \& Ernst, E. E. (2000). The efficacy of distant healing: a systematic review of randomized trials. Annals of Internal Medicine, 132(11), 903-910.

Atmanspacher, H. (2014). Levels of unconsciousness and their formal structure. The Journal of Analytical Psychology, 59(1468-5922 (Electronic)), 385-390.

Atmanspacher, H. (2015). Quantum Approaches to Consciousness. In E. N. Zalta (Ed.), The Stanford Encyclopedia of Philosophy.

Atmanspacher, H. (2016). Synchronistic mind-matter correlations in therapeutic practice: a commentary on Connolly (2015). The Journal of Analytical Psychology, 61(1), 79-85. https://doi.org/10.1111/1468-5922.12196

Badcock, J. C., Dehon, H., \& Larøi, F. (2017). Hallucinations in healthy older adults: an overview of the literature and perspectives for future research. Frontiers in Psychology, 8, 1134. https://doi.org/10.3389/fpsyg.2017.01134

Barlow, P. W. (2015). The natural history of consciousness, and the question of whether plants are conscious, in relation to the Hameroff-Penrose quantum-physical "Orch OR" theory of universal consciousness. Communicative \& Integrative Biology, 8(4), e1041696.

Beischel, J. (2019). Spontaneous, Facilitated, Assisted, and Requested After-Death Communication Experiences and their Impact on Grief. Threshold: Journal of Interdisciplinary Consciousness Studies, 3(1), 1-32.

Beischel, J., Boccuzzi, M., Biuso, M., \& Rock, A. J. (2015). Anomalous information reception byresearch mediums under blinded conditions II: replication and extension. EXPLORE: The Journal of Science and Healing, 11(2), 136-142. https://doi.org/10.1016/J.EXPLORE.2015.01.001

Beischel, J., Mosher, C., \& Boccuzzi, M. (2017). Quantitative and qualitative analyses of mediumistic and psychic experiences. Threshold: Journal of Interdisciplinary Consciousness Studies, 1(2), 51-91.

Beischel, J., \& Zingrone, N. (2015). Mental mediumship. In E. Cardeña, J. Palmer, \& D. Marcusson-Clavertz (Eds.), Parapsychology: A handbook for the 21st century (pp. 301-313). Jefferson, NC: McFarland.

Bengston, W. (2007). Commentary: A Method Used to Train Skeptical Volunteers to Heal in an Experimental Setting. The Journal of Alternative and Complementary Medicine, 13(3), 329-332. https://doi.org/10.1089/acm.2007.6403

Bengston, W. (2012). Spirituality, connection, and cealing with intent: reflections on cancer experiments on laboratory mice. In L. . Miller (Ed.), The Oxford Handbook of Psychology and Spirituality (pp. 548-557). Oxford.

Beseme, S., Bengston, W., Radin, D., Turner, M., \& McMichael, J. (2018). Transcriptional Changes in Cancer Cells Induced by Exposure to a Healing Method. Dose-Response, 16(3), 1-8. https://doi.org/10.1177/1559325818782843

Bilucaglia, M., Pederzoli, L., Giroldini, W., Prati, E., \& Tressoldi, P. E. (2019). EEG correlation at a distance: A re-analysis of two studies using a machine learning approach. F1000Research, 8:43. https://doi.org/10.12688/f1000research.17613.2

Bösch, H., Steinkamp, F., \& Boller, E. (2006). Examining psychokinesis: The interaction of human intention with random number generators--A meta-analysis. Psychological Bulletin, 132(4), 497-523. https://doi.org/10.1037/00332909.132.4.497

Braithwaite, J. J., Samson, D., Apperly, I., Broglia, E., \& Hulleman, J. (2011). Cognitive correlates of the spontaneous outof-body experience (OBE) in the psychologically normal population: evidence for an increased role of temporallobe instability, body-distortion processing, and impairments in own-body transformations. Cortex, 47(1973-8102 (Electronic)), 839-853.

Bresnick, T., \& Levin, R. (2006). Phenomenal qualities of Ayahuasca ingestion and its relation to fringe consciousness and personality. Journal of Consciousness Studies, 13(9), 5-24.

Cardeña, E., \& Facco, E. (2015). Non-Ordinary Mental Expressions. Lausanne, CH: Frontiers Media SA.

Cardeña, E., Lynn J., S., \& Krippner, S. (Eds.). (2014). Varieties of Anomalous Experiences. (2nd ed.). Washington, DC, USA: American Psychological Association.

Carruthers, G. (2015). Who am I in out of body experiences? Implications from OBEs for the explanandum of a theory of self-consciousness. Phenomenology and the Cognitive Sciences, 14(1), 183-197. https://doi.org/10.1007/s11097013-9332-0

Cavanaugh, K. L., \& Dillbeck, M. C. (2017). The Contribution of Proposed Field Effects of Consciousness to the Prevention of US Accidental Fatalities: Theory and Empirical Tests. Journal of Consciousness Studies, 24(1-2), 53-86. 
Charlton, B. G. (2007). Alienation, recovered animism and altered states of consciousness. Medical Hypotheses, 68(03069877 (Print)), 727-731.

Chen, Z., Qi, W., Hood, R. W., \& Watson, P. J. (2011). Common Core Thesis and Qualitative and Quantitative Analysis of Mysticism in Chinese Buddhist Monks and Nuns. Journal for the Scientific Study of Religion, 50(4), 654-670. https://doi.org/10.1111/j.1468-5906.2011.01606.x

Connolly, A. (2015). Bridging the reductive and the synthetic: some reflections on the clinical implications of synchronicity. Journal of Analitical Psychology, 60(1468-5922 (Electronic)), 159-178.

De Foe, A., Al Khafaji, B. E., Pederzoli, L., Prati, E., \& Tressoldi, P. E. (2017). Out-of-Body-Experiences: A Phenomenological Comparison of Different Causes. http://dx.doi.org/10.2139/ssrn.2903827

Dillbeck, M. C., \& Cavanaugh, K. L. (2016). Societal Violence and Collective Consciousness. SAGE Open, 6(2), 1-16. https://doi.org/10.1177/2158244016637891

Dillbeck, M. C., \& Cavanaugh, K. L. (2017). Group Practice of the Transcendental Meditation ${ }^{\circledR}$ and TM-Sidhi ${ }^{\circledR}$ Program and Reductions in Infant Mortality and Drug-Related Death. SAGE Open, 7(1), 1-15. https://doi.org/10.1177/2158244017697164

Duggan, M. (2019). Psychokinesis Research. In Psi Encyclopedia. The Society for Psychical Research. https://psiencyclopedia.spr.ac.uk/articles/psychokinesis-research

Duggan, M., \& Tressoldi, P. (2018). Predictive physiological anticipatory activity preceding seemingly unpredictable stimuli: An update of Mossbridge et al's meta-analysis. F1000Research, 7, 407. https://doi.org/10.12688/f1000research.14330.2

Duma., G.M., Mento, G., Manari, T., Martinelli, M., \& Tressoldi, P. (2017). Driving with Intuition: A Preregistered Study about the EEG Anticipation of Simulated Random Car Accidents. PLOS ONE. https://doi.org/10.1371/journal.pone.0170370

Facco, E. (2012). Near-Death experiences and hypnosis: two different phenomena with something in common. Contemporary Hypnosis \& Integrativre Therapy, 29(3), 284-297.

Facco, E. (2017). Meditation and Hypnosis: Two Sides of the Same Coin? International Journal of Clinical and Experimental Hypnosis, 65(2), 169-188. https://doi.org/10.1080/00207144.2017.1276361

Facco, E., \& Agrillo, C. (2012a). Near-death experiences between science and prejudice. Frontiers in Human Neuroscience, 6(art. 209), 1-7. https://doi.org/10.3389/fnhum.2012.00209

Facco, E., \& Agrillo, C. (2012b). Near-death-like experiences without life-threatening conditions or brain disorders: A hypothesis from a case report. Frontiers in Psychology, 3(art. 490), 1-6. https://doi.org/10.3389/fpsyg.2012.00490

Facco, E., Agrillo, C., \& Greyson, B. (2015). Epistemological implications of near-death experiences and other non-ordinary mental expressions: Moving beyond the concept of altered state of consciousness. Medical Hypotheses, 85(1), 8593. https://doi.org/10.1016/j.mehy.2015.04.004

Facco, E., Lucangeli, D., \& Tressoldi, P. (2017). On the Science of Consciousness: Epistemological Reflections and Clinical Implications. Explore: The Journal of Science and Healing. https://doi.org/10.1016/j.explore.2017.02.007

Facco, E., Testoni, I., Ronconi, L., Casiglia, E., Zanette, G., \& Spiegel, D. (2017). Psychological Features of Hypnotizability: A First Step Towards Its Empirical Definition. International Journal of Clinical and Experimental Hypnosis, 65(1), 98-119. https://doi.org/10.1080/00207144.2017.1246881

Facco, E., Al Khafaji, B. E., \& Tressoldi, P. (2019). In search of the true Self. Journal of Theoretical and Philosophical Psychology, 1-24.

Facco, E., Lucangeli, D., \& Tressoldi, P. (2019). Dr. A.M.-A case of a modern mystic? Implications for psychology and medicine. Spirituality in Clinical Practice, 6(1), 44-65. https://doi.org/10.1037/scp0000171

Facco, E., Casiglia, E., Al Khafaji, B. E., Finatti, F., Duma, G. M., Mento, G., ... Tressoldi, P. (2019). The neurophenomenology of out-of-body experiences induced by hypnotic suggestions. International Journal of Clinical and Experimental Hypnosis, 67(1), 39-68. https://doi.org/10.1080/00207144.2019.1553762

Facco, E., Mendozzi, L., Bona, A., Motta, A., Garegnani, M., Costantini, I., ... Lipari, S. (2019). Dissociative identity as a continuum from healthy mind to psychiatric disorders: epistemological and neurophenomenological implications approached through hypnosis. Medical Hypotheses, 130(109274). https://doi.org/10.1016/j.mehy.2019.109

Facco, E., Fracas, F. \& Tressoldi. P. (2020). Moving beyond the concept of altered state of consciousness: the Non-Ordinary Mental Expressions (NOMEs). Preprint available at: https://mindrxiv.org/b5wyf

Faggin, F. (2019). Silicio. Edizioni Mondadori.

Forman, R. C. K. (1998). What does mysticism have to teach us about consciousness?. Journal of Consciousness Studies, 5(2), 185-201.

Gabbard, G. O., Twemlow, S. W., \& Jones, F. C. (1981). Do "near death experiences" occur only near death?. Journal of Nervous and Mental Disease, 169(0022-3018 (Print)), 374-377.

Giroldini, W., Pederzoli, L., Bilucaglia, M., Caini, P., Ferrini, A., Melloni, S., ... Tressoldi, P. (2016). EEG correlates of social interaction at distance. F1000Research, 4, 457. https://doi.org/10.12688/f1000research.6755.5

Giroldini, W., Pederzoli, L., Bilucaglia, M., Prati, E., \& Tressoldi, P. (2018). Exploring the Brain-to-Brain interaction at a distance: a global or differential relationship? https://doi.org/10.31234/OSF.IO/Z8D65

Haraldsson, E. (1995). Personality and abilities of children claiming previous-life memories. Journal of Nervous and Mental Disease, 183(7), 445-451. https://doi.org/10.1097/00005053-199507000-00004

Haraldsson, E. (2003). Children who speak of past-life experiences: is there a psychological explanation?. Psychology and Psychotherapy: Theory, Research and Practice, 76(1), 55-67

Greyson, B., Fountain, N. B., Derr, L. L., \& Broshek, D. K. (2014). Out-of-body experiences associated with seizures. Frontiers in Human Neuroscience, 8(1662-5161 (Electronic)), 65. 
Griffiths, R., Richards, W., Johnson, M., McCann, U., \& Jesse, R. (2008). Mystical-type experiences occasioned by psilocybin mediate the attribution of personal meaning and spiritual significance 14 months later. Journal of Psychopharmacology, 22(6), 621-632. https://doi.org/10.1177/0269881108094300

Hagelin, J. S. (1987). Is consciousness the unified field? A field theorist's perspective. Modern Science and Vedic Science, 1, 29-87.

Hodge, D. R. (2007). A Systematic Review of the Empirical Literature on Intercessory Prayer. Research on Social Work Practice, 17(2), 174-187. https://doi.org/10.1177/1049731506296170

Holt, L., \& Tickle, A. (2014). Exploring the experience of hearing voices from a first person perspective: A metaethnographic synthesis. Psychology and Psychotherapy: Theory, Research and Practice, 87(3), 278-297. https://doi.org/10.1111/papt.12017

Husserl, E. (1970). The Crisis of European Sciences and Transcendental Phenomenology: An Introduction to Phenomenological Philosophy. Evanstone: Northwestern University Press.

Iudici, A., Quarato, M., \& Neri, J. (2019). The Phenomenon of "Hearing Voices": Not Just Psychotic Hallucinations-A Psychological Literature Review and a Reflection on Clinical and Social Health. Community Mental Health Journal, 55(5), 811-818. https://doi.org/10.1007/s10597-018-0359-0

James, W. (1958). The Varieties of Religious Experience. A Study in Human Nature. New York, NY, USA: Longmans, Green, \& Co.

Katz, D. L., Grgć, I., \& Fendley, T. W. (2018). An ethnographical assessment of project Firefly: A yearlong endeavor to create wealth by predicting FOREX currency moves with Associative Remote Viewing. Journal of Scientific Exploration, 32(1), 21-54.

Kolodziejzyk, G. (2013). Greg Kolodziejzyk's 13-year associative remote viewing experiment results. Journal of Parapsychology, 76, 349-368.

Kuhn, T. S. (1962). The structure of scientific revolutions. Chicago: University of Chicago Press.

Lai, C. F., Kao, T. W., Wu, M. S., Chiang, S. S., Chang, C. H., Lu, C. S., ... Chen, W. Y. (2007). Impact of near-death experiences on dialysis patients: a multicenter collaborative study. American Journal of Kidney Disease, 50(15236838 (Electronic)), 124-132,132.

Lambert, N., Chen, Y. N., Cheng, Y. C., Li, C. M., Chen, G. Y., \& Nori, F. (2013). Quantum biology. Nature Physics, 9(10), 18 .

Lucchetti, G., dos Santos, C. L., Lucchetti, A. L., Schwartz, G. E., \& Nasri, F. (2013). Rare medical conditions and suggestive past-life memories: a case report and literature review. Explore: The Journal of Science and Healing, 9(1878-7541 (Electronic)), 372-376.

Martial, C., Mensen, A., Charland-Verville, V., Vanhaudenhuyse, A., Rentmeister, D., Bahri, M. A., ... \& Faymonville, M. E. (2019). Neurophenomenology of near-death experience memory in hypnotic recall: a within-subject EEG study. Scientific Reports, 9(1), 1-11. https://doi.org/10.1038/s41598-019-50601-6

Marwaha, S. B., \& May, E. (2017). The Star Gate archives: reports of the US government sponsored PSI program -19721995. An overview. Paper Presented at the 60th Annual Convention of the Parapsychological Association (pp. 121).

Marwaha, S. B., \& May, E. (2018). The Star Gate archives: reports of the US government sponsored PSI program-19721995. McFarland: Jefferson., North Carolina, USA

Masayuki, O. (2017). Same-Family cases of the reincarnation type in Japan. Journal of Scientific Exploration, 31(4), 551571.

Masters, K. S., Spielmans, G. I., \& Goodson, J. T. (2006). Are there demonstrable effects of distant intercessory prayer? A meta-analytic review. Annals of Behavioral Medicine, 32(1), 21-26. https://doi.org/10.1207/s15324796abm3201_3

Matlok, J. C. (2019). Signs of Reincarnation: Exploring Beliefs, Cases, and Theory. Lanham, Maryland, USA: Rowman \& Littlefield Publishers.

Meyersburg, C. A., Bogdan, R., Gallo, D. A., \& McNally, R. J. (2009). False memory propensity in people reporting recovered memories of past lives. Journal of Abnormal.Psychology, 118(1939-1846 (Electronic)), 399-404.

Mills, A., \& Tucker, J. B. (2014). Past-Life Experiences. In E. Cardena, S. Lynn, \& S. Krippner (Eds.), Varieties of Anomalous Experiences. (Vol. 2nd, pp. 303-332). Washington, DC: American Psychological Association.

Moody Jr., R. A. (1977). Near-death experiences: dilemma for the clinician. Virginia. Medical, 104(0146-3616), 687-690.

Moody Jr., R. A. (1980). Commentary on "The reality of death experiences: a personal perspective" by Ernst Rodin. Journal of Nervous Mental Disorders, 168(0022-3018 (Print)), 264-265.

Mohseni, M., Omar, Y., \& Plenio, M. B. (2014). Quantum Effects in Biology. Cambridge, UK: Cambridge University Press.

Mossbridge, J., Tressoldi, P., \& Utts, J. (2012). Predictive physiological anticipation preceding seemingly unpredictable stimuli: A meta-analysis. Frontiers in Psychology. 3:390. doi: 10.3389/fpsyg.2012.0039 0

Neppe, V. M., \& Close, E. R. (2015). The concept of relative non-locality: theoretical implications in consciousness research. Explore: The Journal of Science and Healing, 11(1878-7541 (Electronic)), 102-108.

Orme-Johnson, W., D., \& Oates, R. M. (2009). A Field-Theoretic View of Consciousness : Reply to Critics. Journal of Scientific Exploration, 23(2), 139-166.

Palmieri, A., Calvo, V., Kleinbub, J. R., Meconi, F., Marangoni, M., Barilaro, P., ... Sessa, P. (2014). Reality of near-deathexperience memories: evidence from a psychodynamic and electrophysiological integrated study. Frontiers in Human Neuroscience, 8, 429. https://doi.org/10.3389/fnhum.2014.00429

Parnia, S., Spearpoint, K., de, V. G., Fenwick, P., Goldberg, D., Yang, J., ... Schoenfeld, E. R. (2014). AWARE-Awareness during Resuscitation-A prospective study. Resuscitation, 85(12), 1799-1805.

Parnia, S., Spearpoint, K., \& Fenwick, P. B. (2007). Near death experiences, cognitive function and psychological outcomes of surviving cardiac arrest. Resuscitation, 74(2), 215-221. https://doi.org/10.1016/j.resuscitation.2007.01.020 
Pederzoli, L., Prati, E., Resti, N., Del Carlo, D., \& Tressoldi, P. (2018). Hypno-Channelings: A new tool for the investigation of Channeling Experiences. SSRN Electronic Journal. https://doi.org/10.2139/ssrn.3281560

Pederzoli, L., \& Tressoldi, P. E. (2018). A Guide for OBE Induction. SSRN Electronic Journal. https://doi.org/10.2139/ssrn.3148432

Pederzoli, L., Tressoldi, P., \& Wahbeh, H. (2021). Channeling: a non-pathological possession and dissociative identity experience or something else?. Culture, Medicine, and Psychiatry, 1-9. https://doi.org/10.1007/s11013-021-097309

Poznanski, R. R., Tuszynski, J. A., \& Feinberg, T. E. (2017). Biophysics of Consciousness. London, UK: World Scientific Publishing Co. Pte Ltd.

Pyun, Y. D., \& Kim, Y. J. (2009). Experimental Production of Past-Life Memories in Hypnosis. International Journal of Clinical and Experimental Hypnosis, 57(3), 269-278. https://doi.org/10.1080/00207140902881031

Radin, D., Hayssen, G., \& Walsh, J. (2007). Effects of intentionally enhanced chocolate on mood. EXPLORE: The Journal of Science and Healing, 3(5), 485-492. https://doi.org/10.1016/J.EXPLORE.2007.06.004

Radin, D., Bancel, P., \& Delorme, A. (2021). Psychophysical interactions with entangled photons: Five exploratory studies. Journal of Anomalous Experience and Cognition, 1(1-2). https://doi.org/10.31156/jaex.23392

Raatikainen, P. (2018). Gödel's Incompleteness Theorems. In E. N. Zalta (Ed.), The Stanford Encyclopedia of Philosophy (pp. 1-68). Stanford, CA, USA: University of Stanford, CA, US.

Radin, D., Michel, L., \& Delorme, A. (2016). Psychophysical modulation of fringe visibility in a distant double-slit optical system. Physics Essays, 29(1), 14-22. https://doi.org/10.4006/0836-1398-29.1.014

Radin, D., Michel, L., Johnston, J., \& Delorme, A. (2013). Psychophysical interactions with a double-slit interference pattern. Physics Essays, 26(4), 553-566. https://doi.org/10.4006/0836-1398-26.4.553

Sabom, M. B. (1998). Light \& death. Grand Rapids, MI, USA: Zondervan.

Sarraf, M., Woodley, M. \& Tressoldi, P. (2020). Anomalous information reception by mediums: A meta-analysis of the scientific evidence. EXPLORE: The Journal of Science and Healing. https://doi.org/10.1016/j.explore.2020.04.002

Schwartz, S. A. (2018). Finding Saddam Hussein: A study in applied remote viewing. EdgeScience, 5-9.

Schwartz, S. A., \& De Mattei, R. J. (2000). The discovery of an American brig: fieldwork involving applied remote viewing including a comparison with electronic remote sensing. Journal of Scientific Exploration, 34, 1, 62-92; https://doi.org/10.31275/2020/1481

Shiah, Y.-J., \& Radin, D. (2013). Metaphysics of the Tea Ceremony: A randomized trial investigating the roles of intention and belief on mood while drinking tea. EXPLORE: The Journal of Science and Healing, 9(6), 355-360. https://doi.org/10.1016/J.EXPLORE.2013.08.005

Smith, A. M., \& Messier, C. (2014). Voluntary Out-of-Body Experience: An fMRI Study. Frontiers in Human Neuroscience, 8, 70. https://doi.org/10.3389/fnhum.2014.00070

Smith, C. C., Laham, D., \& Moddel, J. (2014). Stock market prediction using associative remote viewing by inexperienced remote viewers. Journal of Scientific Exploration, 28(1), 7-16.

Stevenson, I. (1960). The Evidence for Survival from Claimed Memories of Former Incarnations. Journal of the American Society for Psychical Research, 54, 51-71.

Stevenson, I. (1977). Research into the evidence of man's survival after death: a historical and critical survey with a summary of recent developments. Journal of Nervous Mental Disorders, 165(0022-3018, 152-170.

Stevenson, I. (1994). A case of the psychotherapist's fallacy: Hypnotic regression to "previous lives." American Journal of Clinical Hypnosis, 36(3), 188-193. https://doi.org/10.1080/00029157.1994.10403068

Storm, L., Sherwood, S. J., Roe, C. A., Tressoldi, P. E., Rock, A. J., \& Risio, L. D. (2017). On the correspondence between dream content and target material under laboratory conditions: A meta-analysis of dream-ESP studies, 1966-2016. International Journal of Dream Research, 10(2). https://doi.org/10.11588/ijodr.2017.2.34888

Stubenberg, L. 2018. "Neutral Monism.” In Stanford Encyclopedia of Philosophy, edited by N Zalta, U Nodelman, C Allen, and R Lanier Anderson, 1-67. Stanford University, USA. https://plato.stanford.edu/archives/fall2018/entries/neutral-monism/.

Tarazi, L. (1990). An Unusual Case of Hypnotic Regression with Some Unexplained Contents. Journal of the American Society for Psychical Research, 84, 309-344.

Testoni, I., Facco, E., \& Perelda, F. (2017). Toward A New Eternalist Paradigm for Afterlife Studies: The Case of the NearDeath Experiences Argument. World Futures, 73(7), 1-15. https://doi.org/10.1080/02604027.2017.1357935

Tressoldi, P. E., Pederzoli, L., Caini, P., Ferrini, A., Melloni, S., Richeldi, D., ... Trabucco, A. (2014). Out of Body Experience Induced by Hypnotic Suggestion: Phenomenology and Perceptual Characteristics. https://mindrxiv.org/kgh3t

Tressoldi, P., Pederzoli, L., Bilucaglia, M., Caini, P., Fedele, P., Ferrini, A., ... Accardo, A. (2014). Brain-to-Brain (mind-tomind) interaction at distance: a confirmatory study. F1000Research, 3. https://doi.org/10.12688/f1000research.4336.3

Tressoldi, P. E., Pederzoli, L., Caini, P., Ferrini, A., Melloni, S., Prati, E., ... Trabucco, A. (2015). Hypnotically Induced Out-of-Body Experience: How Many Bodies Are There? Unexpected Discoveries About the Subtle Body and Psychic Body. SAGE Open, 5(4). https://doi.org/10.1177/2158244015615919

Tressoldi, P., Pederzoli, L., Matteoli, M., Prati, E., \& Kruth, J. G. (2016). Can our minds emit light at 7300 km distance? A pre-registered confirmatory experiment of mental entanglement with a photomultiplier. NeuroQuantology, 14(3). https://doi.org/10.14704/nq.2016.14.3.906

Tressoldi P. (2018). Ganzfeld database 1974-2018 [Database]. Retrieved from https://open-data.spr.ac.uk/dataset/19742018-ganzfeld-database

Tressoldi, P. E., Pederzoli, L., Prati, E., \& Semenzato, L. (2020). Mind control at distance of an electronic device: a proofof-concept preregistered study. Journal of Scientific Explorations. https://doi.org/10.31275/2020/1573 
Tressoldi, P., Liberale, L., Sinesio, F., Bubba, V., Pederzoli, L., \& Testoni, I. (2021). Mediumship accuracy: a quantitative and qualitative study with a triple-blind protocol. EXPLORE. https://doi.org/10.1016/j.explore.2021.05.009

Tressoldi, P., \& Pederzoli, L. (2021). What is it like to be in Out-of-Body? Phenomenal accounts of experiencers. https://mindrxiv.org/5vwmg

Tressoldi, P. E., \& Storm, L. (2021). Stage 2 Registered Report: Anomalous perception in a Ganzfeld conditionA meta-analysis of more than 40 years investigation. F1000Research, 10(234), 234. https://doi.org/10.12688/f1000research.51746.1

Tressoldi, P., Álvarez, A. A., Facchin, N., Frullanti, M., Liberale, L., Saad, M., ... \& Testoni, I. (2022). Shared Death Experiences: A Multicultural Survey. American Journal of Hospice and Palliative Medicine.

Trichter, S., Klimo, J., \& Krippner, S. (2009). Changes in spirituality among Ayahuasca ceremony novice participants. Journal of Psychoactive Drugs, 41(2), 121-134. https://doi.org/10.1080/02791072.2009.10399905

Tucker, J. B. (2008). Children's reports of past-life memories: a review. Explore: The Journal of Science \& Healing, 4(1550-8307, 244-248.

Tucker, J. B. (2016). The case of James Leininger: an American case of the reincarnation type. Explore: The Journal of Science \& Healing, 12(3), 200-207. https://doi.org/10.1016/j.explore.2016.02.003

Utts, J. (1996). An assessment of the evidence for psychic functioning. Journal of Scientific Exploration, 10(1), 3-30.

Vaitl, D., Birbaumer, N., Gruzelier, J., Jamieson, G. A., Kotchoubey, B., Kubler, A., ... Weiss, T. (2005). Psychobiology of altered states of consciousness. Psychological Bulletin, 131(0033-2909), 98-127.

van Lommel, P., van Wees, R., Meyers, V., \& Elfferich, I. (2001). Near-death experience in survivors of cardiac arrest: a prospective study in the Netherlands. Lancet, 358(9298), 2039-2045. https://doi.org/10.1016/S01406736(01)07100-8

Varela, F. Neurophenomenology: a methodological remedy to the hard problem. Journal of Consciousness Studies. 1996;3:330-50.

Wahbeh, H., Cannard, C., Okonsky, J., \& Delorme, A. (2019). A physiological examination of perceived incorporation during trance. F1000Research, 8, 67. https://doi.org/10.12688/f1000research.17157.1

Wahbeh, H., Carpenter, L., \& Radin, D. (2018). A mixed methods phenomenological and exploratory study of channeling. Journal of the Society for Psychical Research, 82(3), 129-147.

Wahbeh, H., \& Radin, D. (2018). People reporting experiences of mediumship have higher dissociation symptom scores than non-mediums, but below thresholds for pathological dissociation. F1000Research. https://doi.org/10.12688/f1000research.12019.3

Walach, H., \& Romer, H. (2011). Generalized entanglement - A nonreductive option for a phenomnologically dualist and ontologically monist view of consciousness. In H. Walach, S. Schmidt, \& B. J. Wayne (Eds.), Neuroscience, Consciousness and Spirituality. (pp. 81-96). Dordrecht: Springer.

Wang, Z., Busemeyer, J. R., Atmanspacher, H., \& Pothos, E. M. (2013). The potential of using quantum theory to build models of cognition. Topic in Cognitive Science, 5(1756-8765 (Electronic)), 672-688. 